\title{
Comunicação
}

\section{Emergência e desenvolvimento de mudas de tomate IPA 6 em substratos, contendo esterco ovino ${ }^{1}$}

\author{
Enio Gomes Flôr Souza², Aurélio Paes Barros Júnior ${ }^{3}$, Lindomar Maria da Silveira4, \\ Manoel Galdino dos Santos ${ }^{5}$ Edson Fábio da Silva ${ }^{6}$
}

\section{RESUMO}

A busca por substratos alternativos, que possam substituir produtos comerciais na produção de mudas de tomate, é de fundamental importância para a redução dos custos nessa fase inicial da cultura. Objetivou-se, com esta pesquisa, avaliar a qualidade de mudas de tomate industrial IPA 6, produzidas com substratos à base de esterco ovino. O experimento foi conduzido em viveiro da Universidade Federal Rural de Pernambuco, Unidade Acadêmica de Serra Talhada, de 16 de fevereiro a 30 de março de 2012. Utilizou-se o delineamento inteiramente casualizado, com quatro repetições. Os tratamentos avaliados foram: T1 - [substrato comercial]; T2 - [esterco ovino + areia (1:1)]; T3 - [esterco ovino + areia (2:1)]; T4 - [esterco ovino + areia (3:1)]; T5 - [esterco ovino + solo (1:1)]; T6 - [esterco ovino + solo (2:1)]; $\mathrm{T} 7$ - [esterco ovino + solo (3:1)]; T8 - [esterco ovino + areia + solo (1:1:1)]; T9 - [esterco ovino + areia + solo (2:1:1)]; $\mathrm{T} 10-$ [esterco ovino + areia + solo (3:1:1)]. Os indicadores de emergência avaliados foram: percentagem, índice de velocidade e tempo médio de emergência. Analisaram-se as seguintes características de desenvolvimento: número de folhas, altura de plântula, diâmetro de caule, comprimento de raízes, massa da matéria seca da parte aérea e das raízes. O substrato comercial proporcionou melhor vigor de mudas de tomate IPA 6. Por outro lado, o uso do esterco ovino mais solo (2:1), para compor substratos alternativos constituiu-se opção viável para a produção de mudas desse cultivar.

Palavras-chave: Solanum lycopersicum L., vigor de plântulas, adubo orgânico, resíduo agrícola.

\section{ABSTRACT \\ Emergence and development of tomato IPA 6 seedlings in substrates containing sheep manure}

The search for alternative substrat that can replace commercial products in the tomato seedlings production is very important to reduce costs at the first stage of such culture. The present study aimed to evaluate the quality of industrial tomato IPA 6 seedlings produced with alternative substrate of sheep manure. The experiment was carried ou at a plant nursery at the Universidade Federal Rural de Pernambuco, in Serra Talhada, Pernambuco State, Brazil, from February 16 to March 30, 2012. The experimental design was a completely randomized design with four replications. The treatments were: T1 - commercial substrate; T2 - sheep manure + sand (1:1); T3 - sheep manure + sand (2:1); T4 - sheep manure + sand (3:1); T5 - sheep manure + soil (1:1); T6 - sheep manure + soil (2:1); T7 - sheep manure + soil $(3: 1) ;$ T $8-$ sheep manure + sand + soil $(1: 1: 1) ;$ T $9-$ sheep manure + sand + soil $(2: 1: 1) ;$ T10 - sheep manure + sand + soil

\footnotetext{
Recebido para publicação em 22/08/2012 e aprovado em 03/05/2013

${ }^{1}$ Este trabalho é parte das atividades de iniciação científica do primeiro autor.

${ }^{2}$ Engenheiro-Agrônomo. Universidade Federal Rural de Pernambuco, Unidade Acadêmica de Serra Talhada, Fazenda Saco, Caixa Postal 063, 56900-000, Serra Talhada, Pernambuco, Brasil. eniosouzape @gmail.com (autor para correspondência).

${ }^{3}$ Engenheiro-Agrônomo, PhD. Universidade Federal Rural de Pernambuco, Unidade Acadêmica de Serra Talhada, Fazenda Saco, Caixa Postal 063, 56900-000, Serra Talhada, Pernambuco,Brasil. aurelio02@yahoo.com.br

${ }^{4}$ Engenheira-Agrônoma, Doutora. Departamento de Ciências Vegetais, Universidade Federal Rural do Semiárido, Avenida Francisco Mota, 572, Bairro Costa e Silva, Caixa Postal 137, 59625-900, Mossoró, Rio Grande do Norte, Brasil. lindomarmaria@yahoo.com.br

${ }_{5}^{5}$ Granduando em Engenharia Agronômica. Universidade Federal Rural de Pernambuco, Unidade Acadêmica de Serra Talhada, Fazenda Saco, Caixa Postal 063, 56900-000, Serra Talhada, Pernambuco, Brasil. manoel.galdino5@gmail.com

${ }^{6}$ Engenheiro-Agrônomo. Universidade Federal Rural de Pernambuco, Unidade Acadêmica de Serra Talhada, Fazenda Saco, Caixa Postal 063, 56900-000, Serra Talhada, Pernambuco, Brasil.edsonfabio@agronomo.eng.br
} 
(3:1:1). The emergence indicators were: percentage, speed index and average time of emergence. Regarding the development characteristics of seedlings were analyzed: leaf number, stem diameter, seedling height, root length, shoot dry matter and root dry matter. The commercial substrate provided better vigor of tomato IPA 6 seedlings. Moreover, the use of soil and sheep manure (2:1) to compose alternative substrates consisted of a viable option for seedlings production of this cultivar.

Key words: Solanum lycopersicum L., seedling vigor, organic fertilizer, agricultural waste.

\section{INTRODUÇÃO}

O tomate (Solanum lycopersicum L.) é a principal cultura representante da família Solanaceae, cujo cultivo tem ampla importância social e econômica. Em 2009, a produção brasileira de tomate foi estimada em 4,3 milhões de toneladas, com uma área de 67,69 mil hectares, gerando 2,7 bilhões de reais. Goiás, São Paulo e Minas Gerais são os principais estados produtores, respondendo por quase $62 \%$ da produção nacional. Goiás destaca-se por atingir mais de $33 \%$ da produção de tomate no Brasil, em área de 18,1 mil hectares. No mesmo ano, os estados da Bahia, Pernambuco e Ceará se destacaram com $90 \%$ do total de tomate produzido na região Nordeste (IBGE, 2009).

Praticamente, todo o tomate cultivado na região do Submédio São Francisco é do tipo industrial, sendo consumido in natura, como salada e, em grande parte, como vinagrete (Rocha, 2007). Os cultivares de crescimento determinado são preferidos pelos agricultores, pois apresentam ciclo curto e dispensam o tutoramento e a desbrota, o que reduz os custos de produção. Para o Estado de Pernambuco, Karasawa et al. (2010) afirmam que os entraves atuais na expansão do cultivo do tomate industrial consistem na falta de investimentos, na maioria das propriedades agrícolas, e no baixo nível tecnológico dos produtores.

Em contrapartida, produtores com maior aporte tecnológico, no Nordeste, têm iniciado a utilização de novas práticas de cultivo na tomaticultura industrial, como a irrigação por gotejamento, aliada à fertirrigação, a aplicação de mulching e o uso de sementes híbridas de alta qualidade. Entretanto, ainda são poucos os estudos que indiquem substratos adequados ou alternativos para a produção de mudas de tomate, principalmente aqueles que possam substituir produtos comerciais. A caracterização de resíduos urbanos ou rurais e a avaliação de seu aproveitamento como insumo agrícola pode ser uma importante alternativa para a reciclagem desses materiais (Costa et al., 2009).

Uma tendência geral para compor substratos tem sido a adição de fontes de matéria orgânica, o que contribui não só para o fornecimento de nutrientes, mas também para a melhoria das características físicas do meio de cultivo (Lima et al., 2006). Em algumas regiões ou condições, o esterco é um insumo disponível e de baixo custo, o que tem levado os produtores a considerarem a adubação orgânica uma alternativa viável, do ponto de vista econômico e agronômico (Alencar et al., 2008). Diante do grande rebanho ovino presente no Nordeste, o desenvolvimento de uma tecnologia que utilize o esterco desses animais na formação de mudas de tomate industrial pode ser importante para os produtores rurais. Abundante na região, esse resíduo pode apresentar custo reduzido, já que muitos desses produtores criam ovinos em suas propriedades, ao mesmo tempo em que se dedicam à agricultura.

Por essa razão, o objetivo desta pesquisa foi avaliar a emergência e desenvolvimento de mudas de tomate industrial IPA 6, quando produzidas com substratos alternativos à base de esterco ovino.

\section{MATERIAL E MÉTODOS}

O experimento foi conduzido no viveiro da Fazenda Saco, no município de Serra Talhada, PE, da Universidade Federal Rural de Pernambuco - UFRPE, Unidade Acadêmica de Serra Talhada - UAST (7 57' 15" S, 38 $17^{\circ}$ ' 41" W e altitude aproximada de $498 \mathrm{~m}$ ). O clima é do tipo semiárido, quente e seco, com chuvas de verão, médias anuais térmicas superiores a $25^{\circ} \mathrm{C}$ e pluviosidade média anual de 650 $\mathrm{mm} \mathrm{ano}^{-1}$, com chuvas irregulares (Melo et al., 2008).

$\mathrm{O}$ delineamento experimental utilizado foi o inteiramente casualizado, com quatro repetições. Os tratamentos foram compostos por dez substratos, sendo um substrato comercial e nove, alternativos, utilizando-se do esterco ovino como componente principal: T1 [Substrato comercial]; T2 - [esterco ovino + areia (1:1)]; T3 - [esterco ovino + areia (2:1)]; T4 - [esterco ovino + areia (3:1)]; T5 - [esterco ovino + solo (1:1)]; T6 - [esterco ovino + solo (2:1)]; T7 - [esterco ovino + solo (3:1)]; T8 - [esterco ovino + areia + solo $(1: 1: 1)]$; T9 - [esterco ovino + areia + solo $(2: 1: 1)] ;$ T10 - [esterco ovino + areia + solo (3:1:1)]. Foram realizadas análises químicas dos substratos (Tabela 1). 
Em relação aos constituintes dos substratos alternativos, utilizou-se esterco ovino curtido, solo oriundo do horizonte A de um CAMBISSOLO e areia, obtida no campus da UFRPE-UAST. O esterco, o solo e a areia foram colocados em estufa, à temperatura de $140^{\circ} \mathrm{C}$, durante oito horas, com a finalidade de reduzir a população de fitopatógenos do solo e eliminar a emergência de plantas daninhas. Para o preparo dos substratos, o esterco, o solo e a areia foram tamisados em peneira com malha de $5 \mathrm{~mm}$, e misturados nas combinações determinadas e homogeneizados manualmente.

O substrato comercial utilizado era composto de casca de pinus, turfa e vermiculita expandida, com umidade de 50\%; capacidade de retenção de água de $100 \%$; pH em água de 5,8 (+/-0,5); condutividade elétrica, na proporção água:substrato de $2: 1$ de $1,7(+/-0,3) \mathrm{mS} \mathrm{cm}^{-1}$ e de $5: 1$ de 1,0 (+/-0,3) $\mathrm{mS} \mathrm{cm}^{-1}$ (DDLAgroindústria, 2012).

As sementes de tomate utilizadas foram do cultivar IPA 6, com excelente adaptação às condições do nordeste do Brasil, crescimento determinado e produção de frutos tipo pêra, com coloração vermelha intensa (Hortivale, 2012). A semeadura foi realizada em 16 de fevereiro de 2012, em bandejas de poliestireno expandido, de 128 células, colocando-se uma semente por célula. As bandejas foram dispostas, suspensas sobre uma bancada, a $1,00 \mathrm{~m}$ do solo, e sombreadas a 50\%. Foi feita irrigação diariamente, de modo a atender às exigências hídricas das mudas.

Para avaliação da emergência, a unidade experimental útil foi constituída de 32 células, sendo avaliadas as seguintes características: percentagem de emergência - calculada aos 19 dias após a semeadura (DAS), de acordo com Labouriau \& Valadares (1976); índice de velocidade de emergência - determinado registrando-se diariamente o número de plântulas emersas até 19 DAS, sendo o índice calculado conforme a fórmula proposta por Maguire (1962); tempo médio de emergência - avaliado de acordo com Labouriau \& Valadares (1976). Consideraram-se como emersas as plântulas que apresentavam os cotilédones acima do substrato.

Para análise do desenvolvimento das mudas de tomate, a parcela experimental também consistiu em 32 células, porém, com área útil formada pelas 12 células centrais. Aos 43 DAS, foram avaliadas as características a seguir: número de folhas - contagem das folhas definitivas desenvolvidas; altura de plântula - determinada com régua graduada em centímetros, com as plântulas ainda na bandeja, medindo-se da base do caule até o ápice da última folha; diâmetro do caule - obtido com paquímetro digital (em centímetros), medindo-se o diâmetro das plântulas na região mediana do caule; comprimento da raiz - determinado com a medição das raízes a partir da base das plântulas até suas extremidades, com régua graduada em centímetros; massas da matéria seca da parte aérea e das raízes - obtidas por separação das plântulas em parte aérea e raízes e posterior secagem, em estufa, com circulação de ar forçada, em temperatura constante de $65^{\circ} \mathrm{C}$, por 72 horas, procedendo-se em seguida à pesagem em balança analítica com precisão de $0,001 \mathrm{~g}$.

Os resultados foram submetidos a testes de normalidade dos resíduos e homogeneidade das variâncias. Para as análises de variância, aplicou-se o teste F, sendo as médias agrupadas pelo teste de Scott-Knott $(\mathrm{p}<0,05)$.

\section{RESULTADOS E DISCUSSÃO}

Observaram-se diferenças significativas entre as médias agrupadas pelo teste de Scott-Knott, a 95\% de confiança, para as variáveis de percentagem de emergência (E), índice de velocidade de emergência (IVE) e tempo médio de emergência (TM) (Tabela 2).

Quanto à emergência de plântulas, verificou-se que os tratamentos com os substratos: T1 [comercial], T4 [esterco ovino + areia (3:1)], T5 [esterco ovino + solo

Tabela 1. Resultados da análise química dos substratos utilizados na produção de mudas de tomate industrial IPA 6

\begin{tabular}{|c|c|c|c|c|c|c|c|c|c|c|}
\hline \multirow[t]{2}{*}{ Amostra $^{1}$} & \multirow[t]{2}{*}{$\begin{array}{c}\mathrm{pH} \\
\left(\mathrm{H}_{2} \mathrm{O}\right) \\
\end{array}$} & $\mathbf{A l}^{3+}$ & $\mathrm{Ca}^{2+}+\mathrm{Mg}^{2+}$ & $\mathrm{Ca}^{2+}$ & $\mathbf{M g}^{2+}$ & $\mathbf{N a}^{+}$ & $\mathbf{K}^{+}$ & \multirow{2}{*}{\multicolumn{2}{|c|}{$\underset{\left(\mathrm{mg} \mathrm{dm}^{-3}\right)}{\mathbf{P}} \underset{\left(\mathrm{g} \mathrm{kg}^{-1}\right)}{\mathrm{C}}$}} & \multirow{2}{*}{$\begin{array}{c}\text { MO } \\
\left(\mathrm{g} \mathrm{kg}^{-1}\right)\end{array}$} \\
\hline & & \multicolumn{6}{|c|}{$\mathrm{cmol}_{\mathrm{c}} \mathrm{dm}^{-3}$} & & & \\
\hline $1-\mathrm{SC}$ & 5,83 & 0,08 & 14,05 & 8,25 & 5,80 & 0,18 & 1,54 & 129,25 & 20,60 & 53,13 \\
\hline $2-\mathrm{EO}+\mathrm{A}(1: 1)$ & 8,00 & 0,00 & 6,10 & 4,00 & 2,10 & 0,43 & 0,90 & 161,00 & 14,30 & 24,70 \\
\hline $3-\mathrm{EO}+\mathrm{A}(2: 1)$ & 8,10 & 0,00 & 4,60 & 3,50 & 1,10 & 0,51 & 1,07 & 229,00 & 21,70 & 37,30 \\
\hline $4-\mathrm{EO}+\mathrm{A}(3: 1)$ & 8,30 & 0,00 & 6,50 & 4,60 & 1,90 & 0,47 & 1,08 & 414,00 & 22,10 & 38,20 \\
\hline $5-\mathrm{EO}+\mathrm{S}(1: 1)$ & 7,1 & 0,00 & 7,00 & 6,40 & 2,60 & 0,66 & 1,19 & 219,00 & 22,00 & 38,00 \\
\hline $6-\mathrm{EO}+\mathrm{S}(2: 1)$ & 7,3 & 0,00 & 8,00 & 5,50 & 2,50 & 0,61 & 1,16 & 273,00 & 29,40 & 50,60 \\
\hline $7-\mathrm{EO}+\mathrm{S}(3: 1)$ & 7,4 & 0,00 & 6,80 & 4,90 & 1,90 & 0,61 & 1,23 & 410,00 & 31,50 & 52,00 \\
\hline $8-E O+A+S(1: 1: 1)$ & 7,2 & 0,00 & 5,50 & 3,40 & 2,10 & 0,55 & 1,02 & 174,00 & 10,20 & 17,60 \\
\hline $9-\mathrm{EO}+\mathrm{A}+\mathrm{S}(2: 1: 1)$ & 7,3 & 0,00 & 5,80 & 3,80 & 2,00 & 0,57 & 1,11 & 228,00 & 20,30 & 35,00 \\
\hline $10-E O+A+S(3: 1: 1)$ & 7,5 & 0,00 & 7,00 & 4,80 & 2,20 & 0,55 & 1,16 & 345,00 & 22,40 & 37,00 \\
\hline
\end{tabular}

${ }^{1}$ SC: substrato comercial; EO: esterco ovino; A: areia; S: solo.

Rev. Ceres, Viçosa, v. 60, n.6, p. 902-907, nov/dez, 2013 
(1:1)], T6 [esterco ovino + solo (2:1)], T7 [esterco ovino + solo (3:1)], T8 [esterco ovino + areia + solo $(1: 1: 1)]$ e T10 [esterco ovino + areia + solo $(3: 1: 1)]$ apresentaram resultados que variaram entre 64,84 e $79,69 \%$, sendo as médias deste grupo de tratamentos, superiores às do segundo agrupamento de médias (Tabela 2). Carvalho et al. (2010) também observaram que a percentagem final de emergência de mudas de tomate IPA 6 foi influenciada significativamente pelos diferentes substratos avaliados, tendo-se destacado positivamente o substrato [vermiculita + húmus (3:1)].

Os maiores valores de IVE e o menor tempo médio de emergência também foram obtidos pelo mesmo grupo de substratos: T1 [substrato comercial], T4 [esterco ovino + areia (3:1)], T5 [esterco ovino + solo (1:1)], T6 [esterco ovino + solo $(2: 1)]$, T7 [esterco ovino + solo $(3: 1)]$, T8 [esterco ovino + areia + solo $(1: 1: 1)]$ e T10 [esterco ovino + areia + solo $(3: 1: 1)$ ], proporcionando menores intervalos de dias para completa emergência das mudas. De acordo com Ferreira \& Borguetti (2004), a partir de medidas de tempo médio de emergência pode-se inferir que a emergência rápida é de fundamental importância como estratégia de estabelecimento no ambiente, aproveitando condições ambientais favoráveis ao desenvolvimento do novo indivíduo. Esses substratos devem reunir características adequadas para uma rápida emergência, como condições aeróbicas desejáveis, retenção de água, que possibilite embebição das sementes, e ausência de camada de impedimento, as quais estão relacionadas com a adição de matéria orgânica nos substratos alternativos (Tabela 1).
Conforme mostram análise de variância e o teste de agrupamento de médias (Tabela 3 ) ocorreu diferença significativa $(\mathrm{p}<0,05)$ para todas as características de desenvolvimento de mudas de tomate estudadas.

Para número de folhas, observou-se que o T1 [substrato comercial] apresentou média mais elevada em duas folhas por muda, porém, estatisticamente, foi considerado similar aos tratamentos: T4 [esterco ovino + areia $(3: 1)]$, T5 [esterco ovino + solo (1:1)], T6 [esterco ovino + solo (2:1)], T7 [esterco ovino + solo (3:1)] e T8 [esterco ovino + areia + solo (1:1:1)]. A maior altura média de plântula foi obtida no substrato comercial $(5,68 \mathrm{~cm})$, sendo significativamente superior à dos demais grupos de substratos avaliados (Tabela 3). Dentre às misturas alternativas, o substrato T6 [esterco ovino + solo (2:1)] foi o que proporcionou maior crescimento aéreo das mudas de tomate $(4,71$ $\mathrm{cm})$. Em estudo sobre desenvolvimento de mudas de pimentão em substratos à base de vermicomposto, Santos et al. (2010) também obtiveram maior altura de mudas com o substrato comercial, o que possivelmente está relacionado com sua maior estabilidade física e nutricional, quando comparadas com as das formulações de substratos alternativos.

Maiores valores para diâmetro de caule $(0,18 \mathrm{~cm}$ e 0,15 $\mathrm{cm})$ foram obtidos nos substratos T1 [substrato comercial] e T6 [esterco ovino + solo (2:1)], respectivamente, com valores similares e estatisticamente superiores aos do segundo grupo de tratamentos. O comprimento da parte aérea, combinado com o diâmetro do colo, constitui um dos mais importantes caracteres morfológicos para se estimar o crescimento das mudas após o plantio definiti-

Tabela 2. Resumo das análises de variância e agrupamento de médias de um substrato comercial e nove substratos à base de esterco ovino em relação a três características de emergência avaliadas em mudas de tomate industrial IPA 6

\begin{tabular}{|c|c|c|c|}
\hline \multirow{2}{*}{ Substratos $^{1}$} & \multicolumn{3}{|c|}{ Características avaliadas $^{2}$} \\
\hline & $\mathbf{E}(\%)$ & IVE & TM (dias) \\
\hline $1-\mathrm{SC}$ & $78,91 \mathrm{a}^{3}$ & $2,29 \mathrm{a}$ & $11,08 \mathrm{a}$ \\
\hline $2-\mathrm{EO}+\mathrm{A}(1: 1)$ & $32,81 \mathrm{~b}$ & $0,80 \mathrm{~b}$ & $14,12 \mathrm{~b}$ \\
\hline $3-\mathrm{EO}+\mathrm{A}(2: 1)$ & $54,69 \mathrm{~b}$ & $1,40 \mathrm{~b}$ & $12,97 \mathrm{a}$ \\
\hline $4-\mathrm{EO}+\mathrm{A}(3: 1)$ & $75,00 \mathrm{a}$ & $1,98 \mathrm{a}$ & $12,46 \mathrm{a}$ \\
\hline $5-\mathrm{EO}+\mathrm{S}(1: 1)$ & $79,69 \mathrm{a}$ & $2,16 \mathrm{a}$ & $12,02 \mathrm{a}$ \\
\hline $6-\mathrm{EO}+\mathrm{S}(2: 1)$ & $76,56 \mathrm{a}$ & $2,00 \mathrm{a}$ & $12,89 \mathrm{a}$ \\
\hline $7-\mathrm{EO}+\mathrm{S}(3: 1)$ & $69,53 \mathrm{a}$ & $1,80 \mathrm{a}$ & $12,94 \mathrm{a}$ \\
\hline $8-E O+A+S(1: 1: 1)$ & 78,91 a & $2,15 \mathrm{a}$ & $11,98 \mathrm{a}$ \\
\hline $9-\mathrm{EO}+\mathrm{A}+\mathrm{S}(2: 1: 1)$ & $44,53 \mathrm{~b}$ & $0,99 \mathrm{~b}$ & $15,52 \mathrm{~b}$ \\
\hline $10-\mathrm{EO}+\mathrm{A}+\mathrm{S}(3: 1: 1)$ & $64,84 \mathrm{a}$ & $1,73 \mathrm{a}$ & $12,56 \mathrm{a}$ \\
\hline $\mathrm{F}_{\text {(tratamento) }}$ & $4,94 * *$ & $5,34 * *$ & $5,29 * *$ \\
\hline Média & 65,55 & 1,73 & 12,85 \\
\hline $\mathrm{CV}(\%)$ & 22,49 & 25,51 & 8,32 \\
\hline
\end{tabular}

${ }^{1} \mathrm{SC}$ : substrato comercial; EO: esterco ovino; A: areia; S: solo.

${ }^{2}$ E: percentagem de emergência; IVE: índice de velocidade de emergência; TM: tempo médio de emergência.

${ }^{3}$ Tratamentos com médias seguidas pela mesma letra na coluna são considerados similares pelo teste de Scott-Knott, a 5\% de probabilidade.

** Significativo pelo teste $\mathrm{F}$ a $1 \%$ de probabilidade. 
vo no campo. Por esta razão, o substrato T6 [esterco ovino + solo (2:1)] deve fornecer quantidades satisfatórias de nutrientes, principalmente o fósforo, cujo teor foi aproximadamente duas vezes superior ao contido no substrato comercial (Tabela 1). Além disso, o pH próximo a neutro naquele substrato favorece a maior disponibilidade dos demais nutrientes na solução do solo.

Avaliando-se o comprimento de raízes, verificou-se que o tratamento com o substrato comercial apresentou maior valor médio $(9,82 \mathrm{~cm})$, diferindo dos demais grupos, mas seguido do tratamento T6 [esterco ovino + solo (2:1)] $(7,95 \mathrm{~cm})$, que foi superior aos grupos com o restante dos substratos avaliados. Provavelmente, esses tratamentos apresentaram espaço poroso adequado e sem impedimento físico ao crescimento radicular das mudas. Medeiros et al. (2008) encontraram resultados semelhantes de comprimento de raízes de mudas de tomate IPA $6(9,97 \mathrm{~cm})$, quando produzidas com substrato comercial, em bandejas de 128 células e irrigadas com água de poço. Ao avaliar o desenvolvimento de plântulas de melancia, em substratos com diferentes proporções de esterco ovino, Souza (2011) também obteve maior comprimento de raízes em mudas cultivadas em substrato comercial e em substrato alternativo, com esterco ovino e solo na proporção de $2: 1$. A formação de raízes maiores permite às plântulas explorarem melhor o volume de substrato disponibilizado, possibilitando maior absorção de água, de nutrientes e de oxigênio para o processo respiratório.

A maior massa da matéria seca da parte aérea foi encontrada nas plântulas oriundas do tratamento com substrato comercial $\left(0,038\right.$ g planta $\left.^{-1}\right)$, destacando-se, também, no segundo grupo, os tratamentos T6 [esterco ovino + solo (2:1)], T7 [esterco ovino + solo (3:1)] e T8 [esterco ovino + areia + solo (1:1:1)], cujos valores médios foram 0,022 g planta $^{-1}$ (Tabela 3). Avaliando o efeito de diferentes substratos na produção de mudas de tomate IPA 6, Carvalho et al. (2010) observaram que o substrato comercial e a mistura [vermiculita + húmus (3:1)] formaram plântulas com matéria seca da parte aérea significativamente superior à dos tratamentos com os demais substratos estudados.

Para a matéria seca de raízes, os substratos T1 [comercial], T6 [esterco ovino + solo (2:1)], T7 [esterco ovino + solo $(3: 1)]$ e T9 [esterco ovino + areia $+\operatorname{solo}(2: 1: 1)]$ promoveram valores estatisticamente similares $(0,017$; 0,016; 0,017; 0,013 g planta $^{-1}$, respectivamente), e superiores aos do segundo grupo de substratos. Avaliando-se a produção de matéria seca de raízes juntamente com as demais características, verifica-se que os substratos comercial e T6 [esterco ovino + solo (2:1)] proporcionaram melhor equilíbrio entre o crescimento da parte aérea e o das raízes, formando, assim, mudas com maior resistência a condições adversas após o transplantio, pois apresentam sistema radicular vigoroso, associado ao maior desenvolvimento de folhas, diâmetro de caule e altura de plântula, características que podem favorecer o pegamento no campo e evitar problemas, como o tombamento pelo vento.

Provavelmente, o maior desenvolvimento das mudas de tomate cv. IPA 6, produzidas com os tratamentos com

Tabela 3. Resumo das análises de variância e agrupamento de médias de um substrato comercial e nove substratos à base de esterco ovino em relação a cinco características de desenvolvimento avaliadas em mudas de tomate industrial IPA 6

\begin{tabular}{lcccccc}
\hline & & \multicolumn{5}{c}{ Características avaliadas $^{2}$} \\
\cline { 3 - 7 } Substratos $^{1}$ & $\mathbf{N F}$ & $\begin{array}{c}\mathbf{A P} \\
(\mathbf{c m})\end{array}$ & $\begin{array}{c}\mathbf{D C} \\
(\mathbf{c m})\end{array}$ & $\begin{array}{c}\mathbf{C R} \\
(\mathbf{c m})\end{array}$ & $\begin{array}{c}\text { MSPA } \\
\left(\mathbf{g ~ p l a n t a}^{-1}\right)\end{array}$ & $\begin{array}{c}\text { MSR } \\
\left(\mathbf{g ~ p l a n t a}^{-1}\right)\end{array}$ \\
\hline $1-\mathrm{SC}$ & $2,01 \mathrm{a}^{3}$ & $5,68 \mathrm{a}$ & $0,18 \mathrm{a}$ & $9,82 \mathrm{a}$ & $0,038 \mathrm{a}$ & $0,017 \mathrm{a}$ \\
$2-\mathrm{EO}+\mathrm{A}(1: 1)$ & $0,58 \mathrm{~b}$ & $3,06 \mathrm{~d}$ & $0,12 \mathrm{~b}$ & $6,51 \mathrm{c}$ & $0,015 \mathrm{c}$ & $0,006 \mathrm{~b}$ \\
$3-\mathrm{EO}+\mathrm{A}(2: 1)$ & $0,96 \mathrm{~b}$ & $3,16 \mathrm{~d}$ & $0,11 \mathrm{~b}$ & $5,59 \mathrm{c}$ & $0,008 \mathrm{c}$ & $0,008 \mathrm{~b}$ \\
$4-\mathrm{EO}+\mathrm{A}(3: 1)$ & $1,35 \mathrm{a}$ & $3,81 \mathrm{c}$ & $0,13 \mathrm{~b}$ & $6,42 \mathrm{c}$ & $0,014 \mathrm{c}$ & $0,009 \mathrm{~b}$ \\
$5-\mathrm{EO}+\mathrm{S}(1: 1)$ & $1,43 \mathrm{a}$ & $3,94 \mathrm{c}$ & $0,14 \mathrm{~b}$ & $6,54 \mathrm{c}$ & $0,015 \mathrm{c}$ & $0,011 \mathrm{~b}$ \\
$6-\mathrm{EO}+\mathrm{S}(2: 1)$ & $1,60 \mathrm{a}$ & $4,71 \mathrm{~b}$ & $0,15 \mathrm{a}$ & $7,95 \mathrm{~b}$ & $0,022 \mathrm{~b}$ & $0,016 \mathrm{a}$ \\
$7-\mathrm{EO}+\mathrm{S}(3: 1)$ & $1,27 \mathrm{a}$ & $4,23 \mathrm{c}$ & $0,13 \mathrm{~b}$ & $6,72 \mathrm{c}$ & $0,022 \mathrm{~b}$ & $0,017 \mathrm{a}$ \\
$8-\mathrm{EO}+\mathrm{A}+\mathrm{S}(1: 1: 1)$ & $1,72 \mathrm{a}$ & $4,21 \mathrm{c}$ & $0,14 \mathrm{~b}$ & $5,51 \mathrm{c}$ & $0,022 \mathrm{~b}$ & $0,011 \mathrm{~b}$ \\
$9-\mathrm{EO}+\mathrm{A}+\mathrm{S}(2: 1: 1)$ & $0,97 \mathrm{~b}$ & $3,43 \mathrm{~d}$ & $0,09 \mathrm{~b}$ & $4,08 \mathrm{~d}$ & $0,011 \mathrm{c}$ & $0,013 \mathrm{a}$ \\
$10-\mathrm{EO}+\mathrm{A}+\mathrm{S}(3: 1: 1)$ & $0,87 \mathrm{~b}$ & $3,28 \mathrm{~d}$ & $0,11 \mathrm{~b}$ & $4,36 \mathrm{~d}$ & $0,010 \mathrm{c}$ & $0,005 \mathrm{~b}$ \\
$\mathrm{~F}_{\text {(tratamento) }}$ & $5,34 * *$ & $9,72^{* *}$ & $4,94 * *$ & $8,18 * *$ & $16,98 * *$ & $4,39 * *$ \\
\hline Média & 1,28 & 3,95 & 0,13 & 6,35 & 0,018 & 0,011 \\
\hline CV $(\%)$ & 29,50 & 13,11 & 16,91 & 18,42 & 23,96 & 36,80 \\
\hline
\end{tabular}

${ }^{1} \mathrm{SC}$ : substrato comercial; EO: esterco ovino; A: areia; S: solo.

${ }^{2}$ NF: número de folhas; AP: altura de plântula; DC: diâmetro do caule; CR: comprimento de raízes; MSPA: massa da matéria seca da parte aérea; MSR: massa da matéria seca de raízes.

${ }^{3}$ Tratamentos com médias seguidas pela mesma letra na coluna são considerados similares pelo teste de Scott-Knott, a $5 \%$ de probabilidade.

** Significativo pelo teste $\mathrm{F}$ a $1 \%$ de probabilidade. 
os substratos comercial e T6 [esterco ovino + solo (2:1)], deve-se ao fato de esses substratos apresentarem proporções satisfatórias dos seus constituintes químicos e físicos, de modo a propiciar a formação de plântulas de melhor qualidade.

\section{CONCLUSÕES}

O substrato alternativo formado pela mistura de esterco ovino e solo, na proporção 2:1, devidamente esterilizada, constitui opção para a produção de mudas de tomate industrial IPA 6.

\section{REFERÊNCIAS}

Alencar FHH, Silva WA, Pereira Júnior EB, Damasceno MM \& Souto JS (2008) Crescimento inicial de plantas de sábia em Latossolo degradado do Cariri Cearense sob efeito de estercos e fertilizantes químicos. Revista Verde, 3:1-5.

Carvalho TG, Pires MMML, Barros JP, Pimenta RMB, Santos JP \& Aragão CA (2010) Efeito de diferentes substratos na produção de mudas de tomateiro. In: $50^{\circ}$ Congresso Brasileiro de Olericultura, Guarapari. Anais, ABH. CD-ROM.

Costa LM, Andrade JWS, Rocha AC, Souza LP \& Flávio Neto J (2009) Avaliação de substratos para o cultivo de pepino (Cucumis sativus L.). Global Science and Technology, 2:21-26.

DDL Agroindústria (2012) Plantmax Hortaliças. Disponível em: <http://www.ddlagro.com.br/plantmax.html>. Acessado em: 4 de abril de 2012.

Ferreira AG \& Borghetti F (2004) Germinação: do básico ao aplicado. Porto Alegre, Artmed. 323p.

Hortivale (2012) Tomate Caline IPA 6. Disponível em: <http:// www.hortivale.com.br/>. Acessado em: 3 de maio de 2012

Instituto Brasileiro de Geografia e Estatística - IBGE (2009) Produção agrícola municipal: culturas temporárias e permanentes. Rio de Janeiro, IBGE. 93p.

Karasawa M, Mesquita JCP, Menezes D, Ferraz E \& Silva MCL (2010) Potencial produtivo de tomateiros rasteiros em vasos. In: $50^{\circ}$ Congresso Brasileiro de Olericultura, Guarapari. Anais, ABH. CD-ROM.

Labouriau LG \& Valadares MB (1976) On the germination of seeds of Calotropis procera. In: Academia Brasileira de Ciências, São Paulo. Anais, Academia Brasileira de Ciências. p.174186 .

Lima RLS, Severino LS, Silva MIL, Jerônimo JF, Vale LS \& Beltrão NEM (2006) Substratos para produção de mudas de mamoneira compostos por misturas de cinco fontes de matéria orgânica. Ciência e Agrotecnologia, 30:474-479.

Maguire JD (1962) Speed of germination and in selection and evaluation for seedling emergence and vigor. Crop Science, $2: 176-177$

Medeiros MA, Freitas AVL, Guimarães IP, Madalena JAS \& Maracajá PB (2008) Produção de mudas de tomateiro em bandejas multicelulares e irrigadas com efluente de piscicultura. Revista Verde, 3:59-63.

Melo RO, Pacheco EP, Menezes JC \& Cantalice JRB (2008) Susceptibilidade à compactação e correlação entre as propriedades físicas de um Neossolo sob vegetação de caatinga. Caatinga, $21: 12-17$
Rocha RC (2007) Uso de diferentes telas de sombreamento no cultivo protegido do tomateiro. Tese de Doutorado. Universidade Estadual Paulista "Júlio de Mesquita Filho", Botucatu. 90p.

Santos MR, Sediyama MAN, Salgado LT, Vidigal SM \& Reigado FR (2010) Produção de mudas de pimentão em substratos à base de vermicomposto. Bioscience Journal, 26:572-578.

Souza EGF (2011) Produção de mudas de cucurbitáceas com substratos à base de esterco ovino. Monografia. Universidade Federal Rural de Pernambuco, Serra Talhada. 62p. 